\title{
A Novel Maximum Power Point Tracking Algorithm Based on Glowworm Swarm Optimization for Photovoltaic Systems
}

\author{
Wenhui Hou, Yi Jin, Changan Zhu, and Guiqiang Li \\ School of Engineering Science, University of Science and Technology of China, Hefei 230026, China \\ Correspondence should be addressed to Yi Jin; jinyi08@ustc.edu.cn and Changan Zhu; changan@ustc.edu.cn
}

Received 26 January 2016; Revised 1 April 2016; Accepted 6 April 2016

Academic Editor: Zbigniew Leonowicz

Copyright ( 2016 Wenhui Hou et al. This is an open access article distributed under the Creative Commons Attribution License, which permits unrestricted use, distribution, and reproduction in any medium, provided the original work is properly cited.

\begin{abstract}
In order to extract the maximum power from PV system, the maximum power point tracking (MPPT) technology has always been applied in PV system. At present, various MPPT control methods have been presented. The perturb and observe (P\&O) and conductance increment methods are the most popular and widely used under the constant irradiance. However, these methods exhibit fluctuations among the maximum power point (MPP). In addition, the changes of the environmental parameters, such as cloud cover, plant shelter, and the building block, will lead to the radiation change and then have a direct effect on the location of MPP. In this paper, a feasible MPPT method is proposed to adapt to the variation of the irradiance. This work applies the glowworm swarm optimization (GSO) algorithm to determine the optimal value of a reference voltage in the PV system. The performance of the proposed GSO algorithm is evaluated by comparing it with the conventional P\&O method in terms of tracking speed and accuracy by utilizing MATLAB/SIMULINK. The simulation results demonstrate that the tracking capability of the GSO algorithm is superior to that of the traditional $\mathrm{P} \& \mathrm{O}$ algorithm, particularly under low radiance and sudden mutation irradiance conditions.
\end{abstract}

\section{Introduction}

In the past few decades, the world's energy demand has risen steadily with the growth of the population and the change in people's lifestyles. However, traditional fuels are limited, and environmental conditions worsen on a daily basis. These conditions urge people to seek renewable energy. Solar energy is a promising renewable energy because of its various advantages, such as limitlessness, zero production of pollution and noise, and good reliability. Hence, photovoltaic $(\mathrm{PV})$ power systems have gained increasing attention from governments and researchers in various countries. Global PV power technology has developed rapidly because of government support. However, two major defects hinder its development: the high installation cost of the system and its low photoelectric conversion efficiency at 9\%-17\% [1]. Improving the maximum power tracking technology to extract the highest amount of power from PV systems is one of the most practical methods to address this problem.

The basic concept of maximum power point tracking (MPPT) is to adjust the operating point of a converter up to the maximum in real time such that the system can constantly operate at the maximum power point (MPP). In this way, MPPT improves conversion efficiency and reduces power loss. However, the MPP changes with the variable external environment, thereby further complicating the maximum power tracking problem [2].

In recent years, many MPPT control methods have been proposed. A detailed description and classification of numerous MPPT techniques are made by Subudhi and Pradhan [3]. Among these methods, the most commonly used approaches are perturb and observe $(\mathrm{P} \& \mathrm{O})$ [4-6] and incremental conductance (IncCon) [7-9]. A traditional P\&O algorithm does not need to understand the characteristics of a PV system. Thus, this algorithm is simple and easy to develop. It works by imposing a fixed step perturbation on a reference voltage or current, measuring the output power of the PV system, and comparing the values before and after disturbance to determine the direction of the disturbance for the next step. If PV power increases, then the direction of the disturbance is the same as that in the last step (i.e., the system is moving toward the MPP); otherwise, the direction is reversed [4]. Despite the simple structure of the $\mathrm{P} \& \mathrm{O}$ algorithm, the fluctuation among the MPP is 
inevitable. In the selection of the tracking step, it is difficult to take account of both tracking precision and response speed. In some instances, the $\mathrm{P} \& \mathrm{O}$ algorithm generates an erroneous direction when a sudden change in irradiance occurs. By contrast, the incremental conductance method is used to determine the disturbance of a control parameter by comparing incremental conductance with instantaneous conductance. The tracking performances of four conventional methods including the constant voltage method, the IncCon method, the $\mathrm{P} \& \mathrm{O}$ method, and the variable step size perturb and observe are compared under fixed solar insolation by Mohanty et al. [9]. The results show that the proportion of the respond time between the IncCon method and the $\mathrm{P} \& \mathrm{O}$ method is about $1: 2$. However, the IncCon method has the same limitation as the $\mathrm{P} \& \mathrm{O}$ algorithm. To overcome these disadvantages, many researchers explored a new direction for MPPT control, which combines artificial intelligence and evolutionary computation techniques [2]. The main methods for MPPT control are artificial neural networks (ANN) [2, 10, 11] and fuzzy logic control (FLC) $[12,13]$. A MPPT technique based on the ANN method which is compared with the traditional $\mathrm{P} \& \mathrm{O}$ algorithm is proposed by Rezk and Hasaneen [11]. The simulation results show that the tracking speed of the proposed method is faster than the traditional P\&O. The proportion of the respond time is about $3: 7$ at high radiation change rate. The comparison between the advanced methods (FLC) and the conventional methods $(\mathrm{P} \& \mathrm{O})$ is presented by Bendib et al. [13]. The simulation results show the performance of the FLC based method is better than the conventional methods, and the proportion of the respond time between them is about $4: 15$. These methods do not require an accurate mathematical model. However, they entail training a large amount of data; hence, the calculation is complex, and a large storage space is necessary. In addition, most of the MPPT methods require the expensive current sensor, which increases the inherent cost of the PV system. In order to reduce costs, many MPPT technologies without the current sensor have been proposed over the last decade. A review and summary of some main current sensorless MPPT technologies are made by Samrat et al. [14]. With the development of bionic algorithms, more and more scholars focused on these algorithms, such as genetic algorithms, artificial bee colony algorithm (ABC), and particle swarm optimization algorithms [15]. Many scholars have employed these bioinspired algorithms for the MPPT of PV systems [16-19].

Glowworm swarm optimization (GSO), which is a new type of bioinspired algorithm, shows superior performance in dealing with nonlinear problems, although this approach has yet to be applied in PV systems. In this work, the GSO algorithm is used to track the MPP of a PV system. To evaluate the performance of the algorithm, the proposed GSObased MPPT method is implemented on a boost converter, and its performance is compared with that of the traditional $\mathrm{P} \& \mathrm{O}$ algorithm.

The information on the PV and boost converter is presented in Section 2. The proposed algorithm is discussed in Section 3. The simulation of MPPT using SIMULINK and

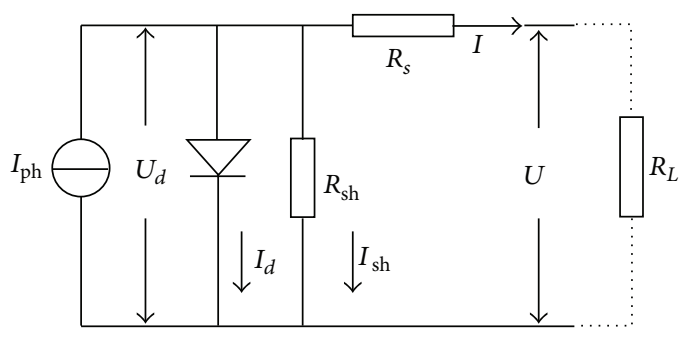

FIGURE 1: Equivalent circuit of a PV cell.

a discussion of the results are shown in Section 4. Finally, the conclusion is presented in Section 5.

\section{PV and Boost Converter Model}

2.1. PV Equivalent Circuit Model. A PV module is used to convert sunlight into direct current and thus facilitates the conversion of light energy to electric energy. A PV-based system can be independently used for streetlights, water pumps, and grid connected systems [20].

The typical equivalent circuit model of a PV cell is a single diode (Figure 1), which consists of a photo current, a diode, a series resistor, and a parallel shunt resistor.

Based on Kirchhoff's current law, the mathematical equation for the output current of an ideal cell is given by

$$
I=I_{\mathrm{ph}}-I_{d}-I_{\mathrm{sh}},
$$

where $I_{\mathrm{sh}}$ is the parallel resistance current and $I_{\mathrm{ph}}$ is the lightgenerated current, which is proportional to the intensity of light. It can be calculated by

$$
I_{\mathrm{ph}}=\left[I_{\mathrm{sc}}+K_{I}\left(T_{c}-T_{r}\right)\right] \cdot G,
$$

where $I_{\mathrm{sc}}$ is the short-circuit current at STC $\left(T=25^{\circ} \mathrm{C}, S=\right.$ $1000 \mathrm{~W} / \mathrm{m}^{2}$ ) and $K_{I}$ is the short-circuit current temperature coefficient of the cell. $T_{c}$ and $T_{r}$ are the operating temperature of the cell and the reference temperature, respectively. $G$ is the relative irradiance coefficient, which is calculated by $S / 1000$ ( $G=1$ under nominal condition).

$I_{d}$ is the diode current, which, according to the Shockley equation, is given by

$$
I_{d}=I_{O}\left[\exp \left(\frac{q U_{d}}{A k T_{c}}\right)-1\right]
$$

where $q$ is the electronic charge $\left(q=1.6 \times 10^{-19}\right), k$ is Boltzmann's constant $\left(k=1.38 \times 10^{-23}\right), A$ is the ideal factor of the diode, $I_{O}$ is the reverse saturation current of the diode, and $U_{d}$ is the voltage of the equivalent diode. According to Kirchhoff's voltage law, $U_{d}$ is given by

$$
U_{d}=U+I R_{s},
$$

where $R_{s}$ is the series resistance.

The voltage and current generated by a single PV cell are very low. Thus, PV cells are usually connected in series and parallel to achieve the desired power. A PV module is usually 
TABLE 1: Parameters of the PV module type CS6X-305P.

\begin{tabular}{lc}
\hline Parameter & Value \\
\hline Maximum power $\left(P_{\max }\right)$ & $305 \mathrm{~W}$ \\
Open-circuit voltage $\left(U_{\mathrm{oc}}\right)$ & $44.8 \mathrm{~V}$ \\
Short-circuit current $\left(I_{\mathrm{sc}}\right)$ & $8.97 \mathrm{~A}$ \\
Number of cells $\left(N_{s}\right)$ & 72 \\
Ideal factor $(A)$ & 1.3 \\
\hline
\end{tabular}

connected in series by batteries, and the series number is generally $26,36,54$, or 72 .

The output current equation of the PV module is given by

$$
\begin{aligned}
I= & I_{\mathrm{ph}}-I_{O}\left[\exp \left(\frac{q\left(U+I \cdot R_{s}\right)}{A k T_{c} N_{s}}\right)-1\right] \\
& -\frac{\left(U+I \cdot R_{s}\right)}{R_{p}},
\end{aligned}
$$

where $N_{s}$ is the number of series resistance cells and $R_{p}$ is the parallel resistance, which is very high that its current can be neglected [14]. Equation (5) can be simplified as

$$
I=I_{\mathrm{ph}}-I_{O}\left[\exp \left(\frac{q\left(U+I \cdot R_{s}\right)}{A k T_{c} N_{s}}\right)-1\right],
$$

where $I_{O}$ varies with the change in temperature and is given by

$$
I_{O}=I_{\text {ro }}\left(\frac{T_{c}}{T_{r}}\right)^{3} \exp \left[\frac{q E_{g}\left(1 / T_{r}-1 / T_{c}\right)}{A k}\right],
$$

where $E_{g}$ is the band gap energy of the semiconductor and $I_{\text {ro }}$ is the saturation current of the diode at $25^{\circ} \mathrm{C}$, which is calculated by

$$
I_{\text {ro }}=\frac{I_{\mathrm{sc}}}{\left[\exp \left(q U_{\mathrm{oc}} / A k T_{r} N_{s}\right)-1\right]},
$$

where $U_{\mathrm{oc}}$ is the open-circuit voltage of the PV module at STC $\left(T=25^{\circ} \mathrm{C}, S=1000 \mathrm{~W} / \mathrm{m}^{2}\right)$.

2.2. Simulation of the PV Module. According to the mathematical model of the PV module, output power depends on two factors, namely, irradiance and temperature. The present work focuses on the influence of irradiance (assuming that the temperature is $25^{\circ} \mathrm{C}$ ). The parameters of the PV module type CS6X-305P used in the simulation are listed in Table 1. The module is composed of 72 solar cells connected in series to achieve a maximum power output of $305 \mathrm{~W}$.

The simulation of the considered PV under variable irradiance via SIMULINK is illustrated in Figure 2.

Figures 3 and 4 present the current-voltage $(I-V)$ characteristic and power-voltage $(P-V)$ characteristic of the PV module, respectively. The maximum power of the $\mathrm{PV}$ is achieved at the extreme point of the $P-V$ curve, which is known as the MPP. The maximum power and short-circuit current increase with irradiance.

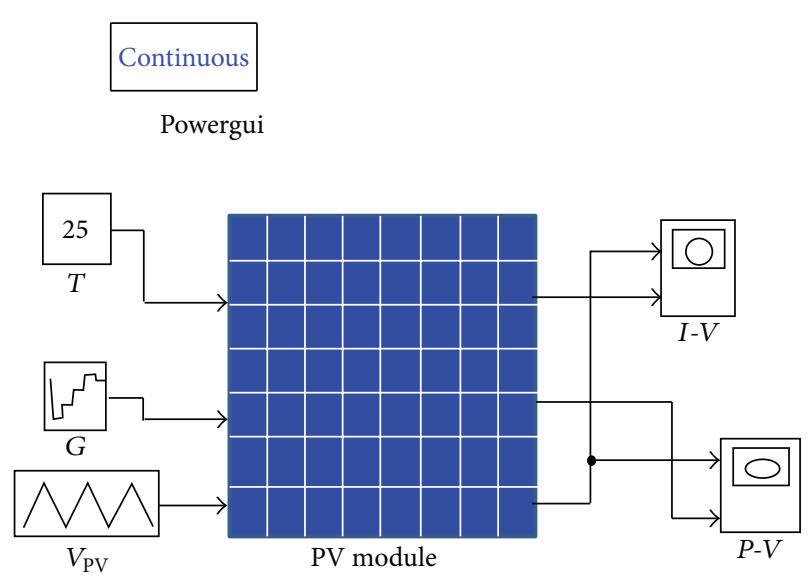

FIGURE 2: PV module with radiance variation.

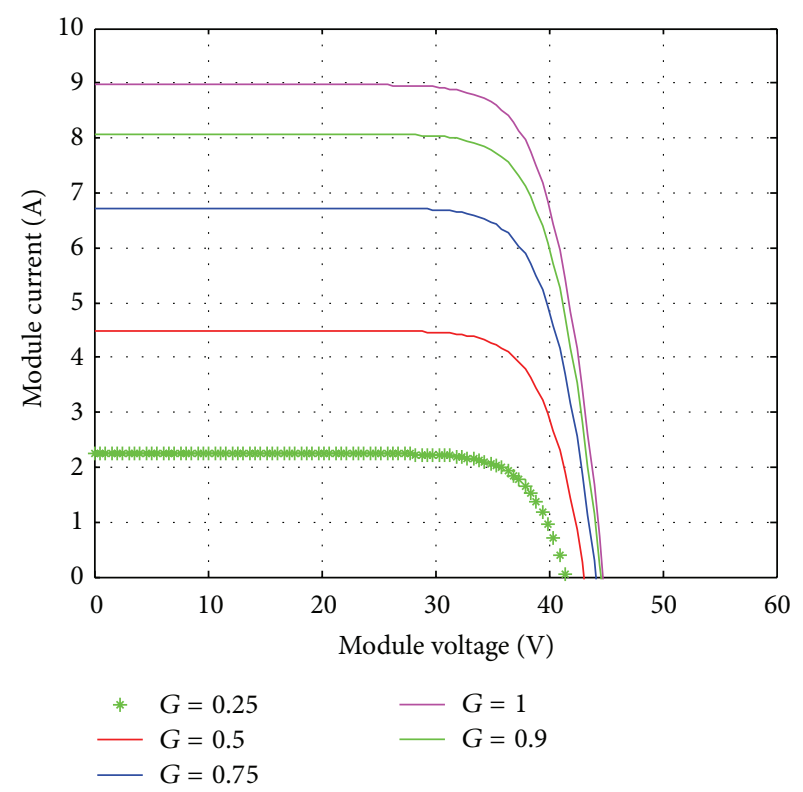

FIGURE 3: $I-V$ characteristic of the PV module under different radiances.

2.3. Boost Converter and Its Simulation. Generally, MPPT is used to track the MPPs of PV systems. The efficiency of MPPT mainly depends on the MPPT control algorithm and MPPT circuit. The MPPT circuit usually uses a DC-DC converter [21]. In the present work, a boost converter is used for MPPT to adjust the operating voltage by changing the duty cycle of the switch. The voltage gain of the converter is calculated by

$$
G_{n}=\frac{U_{\text {out }}}{U_{\text {in }}}=\frac{1}{1-D},
$$

where $D$ is the duty cycle of the switch.

Figure 5 shows the subsystem of the boost converter in SIMULINK. Figure 6 indicates that the converter is connected to the PV module. The input of the boost converter is the output of the PV module. The simulation results of the system at constant $D$ and variable $D$ are shown in Figures 7 and 8 , respectively. 


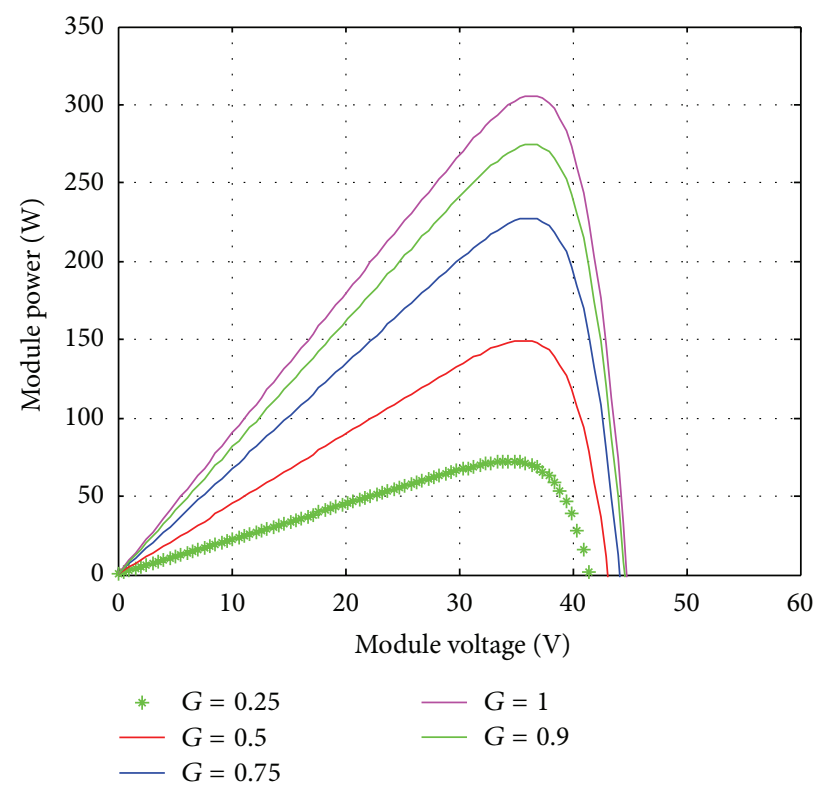

Figure 4: $P-V$ characteristic of the PV module under different radiances.

Figure 7 illustrates the output current and voltage of the boost converter at constant $D(D=0.34)$. Figure 8 demonstrates the influence of different input duty cycles on the output power of a PV system. The figure indicates that an optimal duty cycle allows the PV system to function at the MPP.

\section{Glowworm Swarm Optimization}

The GSO algorithm, which is a new type of stochastic and metaheuristic optimization algorithm, was first proposed by Indian scholars [22]. GSO uses a swarm of glowworms as its agents, which are regarded as the potential solutions to a problem. The fitness of optimality is measured by the objective function defined by users. In the present work, GSO is adopted to generate an optimal reference voltage that varies with radiance to extract the maximum power from the PV module. GSO is an optimization method that is easy to implement with a rapid convergence speed and few parameters to adjust.

3.1. Description of the Algorithm. The GSO algorithm is based on glowworms, each of which is considered a potential solution to the given objective problem. In the first iteration, a swarm of glowworms is randomly distributed in a search space with an initial luciferin value, which determines the brightness of the glowworms. The luciferin is updated according to the objective function value at the current position of the glowworm. Each glowworm, which has its own decision radius $0<r_{d}^{i}<r_{s}\left(r_{s}\right.$ is the largest sensing radius of glowworms), seeks a bright individual with high luciferin in its local-decision range and moves toward such individual. After such move, the decision radius of this glowworm is updated according to the number of optimal individuals in a decision radius. Finally, most of the glowworms gather at the peak point after several iterations. Each iteration consists of a luciferin-update phase, a movement phase based on a transition rule, and a local-decision range update phase [23].

3.1.1. Luciferin-Update Phase. Updating luciferin mainly depends on the objective function value of the current position. At the same time, the decay in luciferin with time should be eliminated. Thus, the formula for updating luciferin is given by

$$
I_{i}(t+1)=(1-\rho) * I_{i}(t)+\gamma * F\left(x_{i}(t+1)\right),
$$

where $\rho$ is the luciferin decay constant $(0<\rho<1), \gamma$ is the luciferin enhancement constant, $I_{i}(t)$ and $I_{i}(t+1)$ are the luciferins at iterations $t$ and $t+1$, respectively, and $F\left(x_{i}(t+1)\right)$ represents the value of the objective function at agent $i$ 's location at iteration $t+1$. In this work, objective function $F$ is the output power of the PV module, which is calculated by

$$
F=P_{\mathrm{PV}}=U * I,
$$

where the relationship between $U$ and $I$ can be derived from (1)-(8) in Section 2. Thus, $F$ is the function of $G$ and $U, G$ is the system variable, and $U$ is the parameter to be optimized, which is regarded as the location of the glowworm.

3.1.2. Movement Phase. Each agent is attracted by a superior individual, but such attraction is limited by the perception range of the individual. Thus, the neighborhood of the agent should be first defined by

$$
N_{i}(t)=\left\{j: d_{i, j}(t)<r_{d}^{i}, I_{i}(t)<I_{j}(t)\right\} .
$$

$d_{i, j}(t)=\left\|x_{i}-x_{j}\right\|$ represents the Euclidean distance between glowworms $i$ and $j$ at iteration $t$.

The probability that glowworm $i$ moves toward neighbor $j$ is given by

$$
p_{i j}=\frac{I_{j}(t)-I_{i}(t)}{\sum_{m \in N_{i}(t)} I_{m}(t)-I_{i}(t)} .
$$

The location update formula for this movement can be stated as follows:

$$
x_{i}(t+1)=x_{i}(t)+s *\left(\frac{x_{j}(t)-x_{i}(t)}{\left\|x_{j}(t)-x_{i}(t)\right\|}\right),
$$

where $s$ is the step size and $x_{i}(t)$ and $x_{i}(t+1)$ are the locations at iterations $t$ and $t+1$, respectively.

3.1.3. Local-Decision Range Update Phase. If many individuals with high luciferin values exist in the local-decision range of glowworm $i$, the decision radius should be appropriately reduced. The update formula of the decision radius is

$$
\begin{aligned}
& r_{d}^{i}(t+1) \\
& \quad=\min \left\{r_{s}, \max \left\{0, r_{d}^{i}(t)+\beta *\left(n_{t}-\left|N_{i}(t)\right|\right)\right\}\right\},
\end{aligned}
$$

where $\beta$ is the variation coefficient of the decision radius and $n_{t}$ is the number of outstanding individuals with high luciferin values in the local-decision range. 


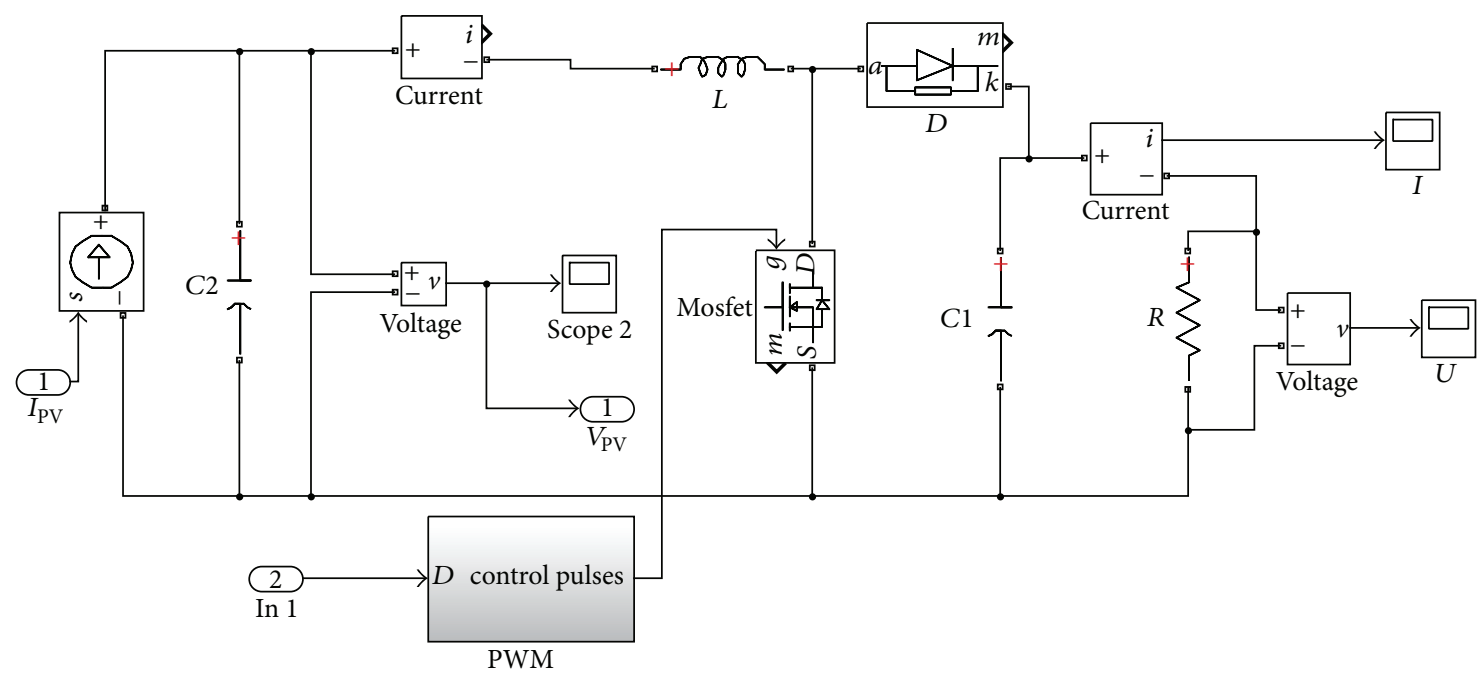

FIgURE 5: Subsystem of boost converter.

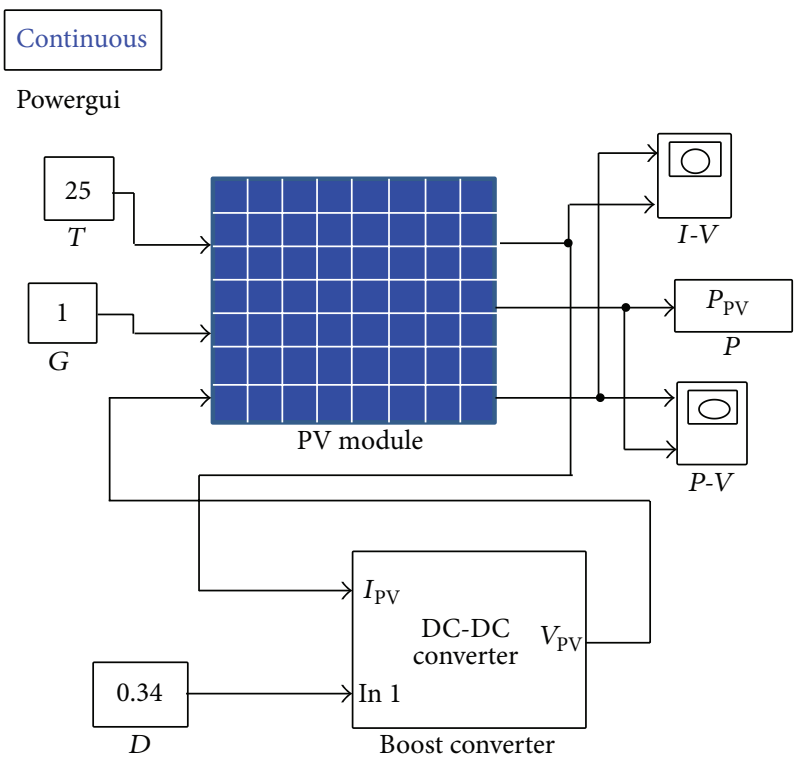

Figure 6: PV-fed DC-DC boost converter.

3.2. Flowchart of the Algorithm. The flowchart of the GSO algorithm is shown in Figure 9.

\section{Simulation of MPPT Using SIMULINK and Result Discussion}

4.1. Simulation of MPPT. In this work, the GSO algorithm is adopted to optimize the reference voltage of the PV system under invariant and variant radiances. The boost converter adjusts the duty cycle of the switch according to the reference voltage. Finally, the output power of the PV system is controlled. The simulation result of the GSO algorithm is compared with that of the traditional $\mathrm{P} \& \mathrm{O}$ algorithm under the constant irradiance. The structure diagram of the system is presented in Figure 10.
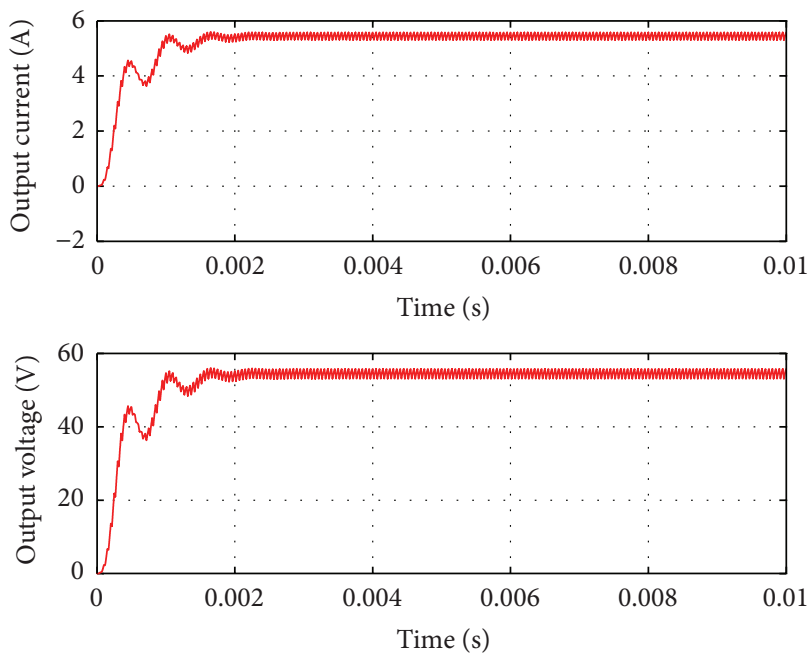

FIGURE 7: Output current and voltage of boost converter at constant D.

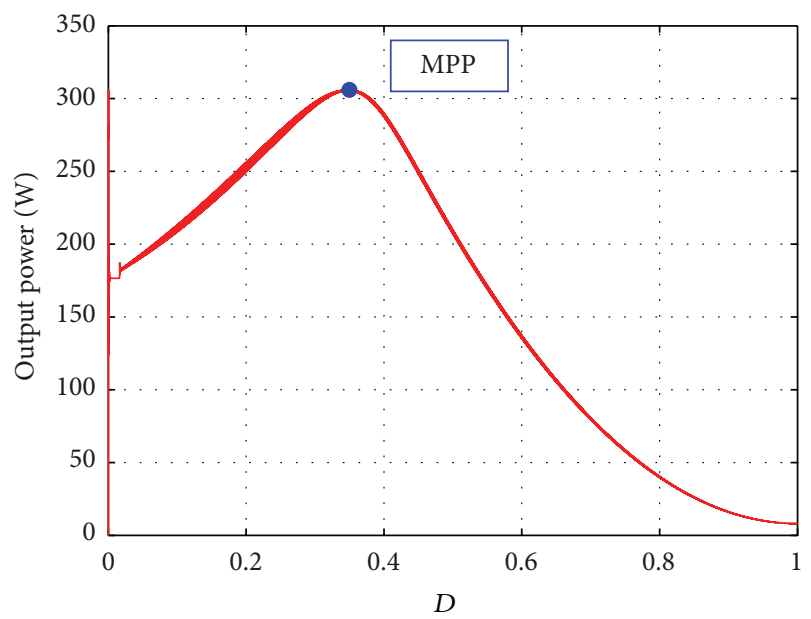

FIgURE 8: Output power of PV at variable $D$. 


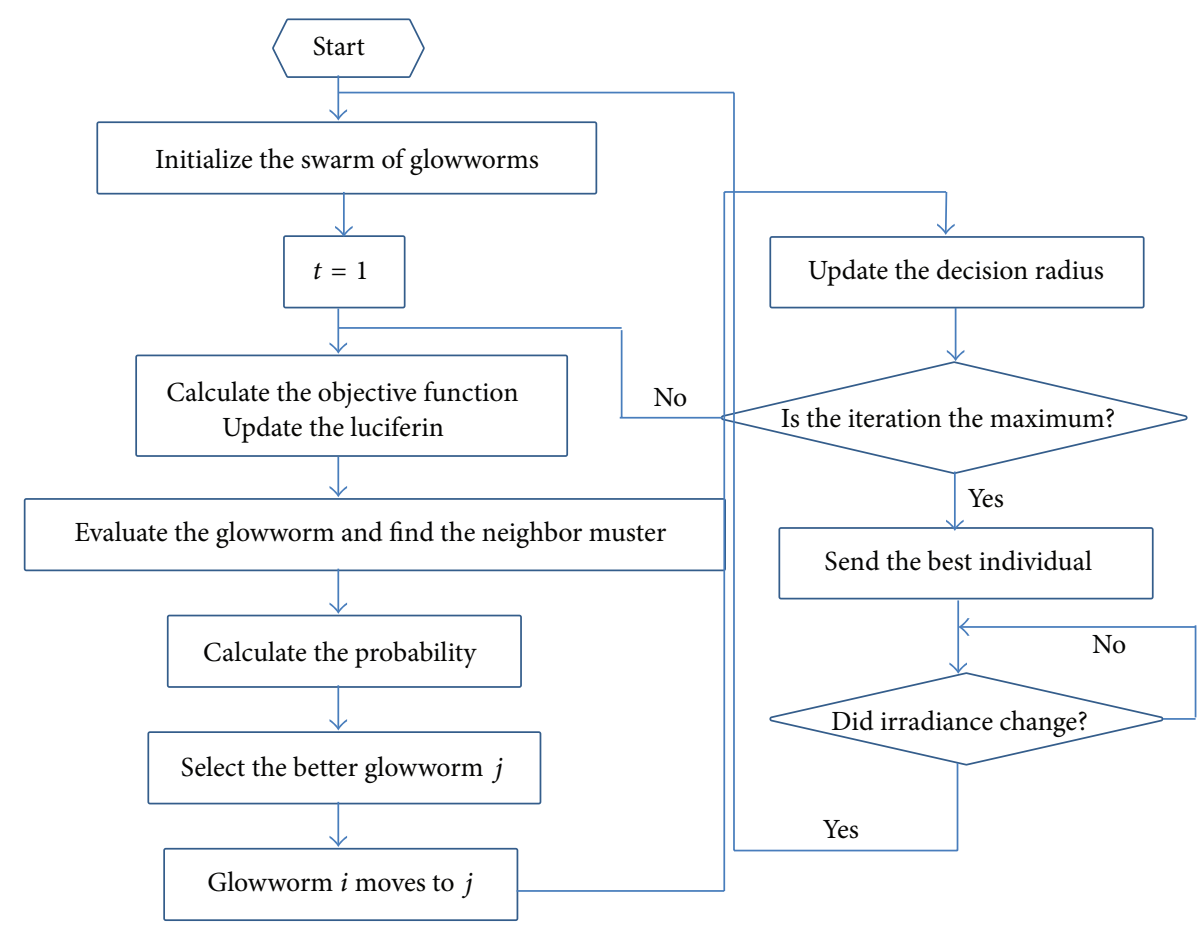

FIGURE 9: Flowchart of the GSO algorithm.

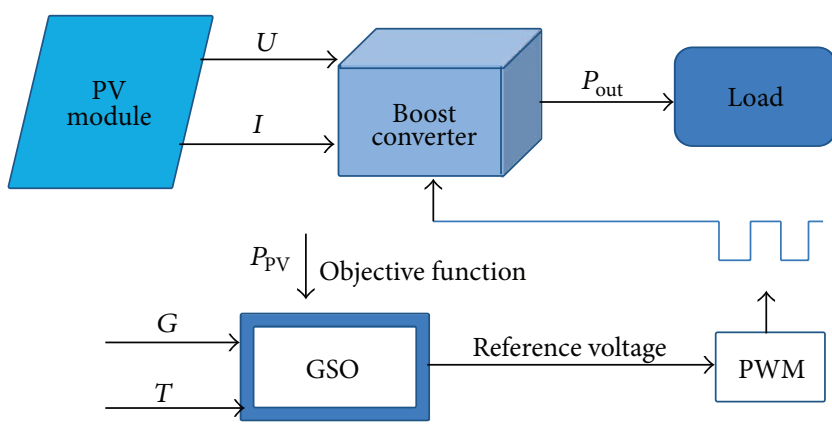

FIgUre 10: Typical diagram of MPPT using GSO.

The proposed GSO algorithm and conventional P\&O method are simulated using MATLAB/SIMULINK. The PV module temperature is considered to be unchanged at $25^{\circ} \mathrm{C}$ during the simulation. Figure 11 presents the simulation of the GSO approach for the considered PV system.

Pulse width modulation (PWM) is a technique to create control pulses for switches. PWM is carried out in SIMULINK, as shown in Figure 12.

The proposed scheme is simulated under two conditions: constant radiance (including high and low irradiance) and variable irradiance (mutation in irradiance).

4.2. Discussion of Results. Figure 13 illustrates the output power of the PV module for the GSO method and conventional method at $1000 \mathrm{~W} / \mathrm{m}^{2}, 25^{\circ} \mathrm{C}$. The figure indicates that the tracking efficiency of the proposed GSO algorithm is higher than that of the traditional P\&O algorithm. The proportion of the respond time between them is about $1: 6$. Different tracking effects for $\mathrm{P} \& \mathrm{O}$ could be shown when various step sizes are used. This work selects a result with small and steady oscillations but slow tracking speed.

Figure 14 illustrates the output power of the PV module for the GSO method and conventional method under low solar radiance $\left(300 \mathrm{~W} / \mathrm{m}^{2}, 25^{\circ} \mathrm{C}\right)$. The result indicates that the GSO algorithm can track the theoretical maximum power, whereas the conventional P\&O method has low efficiency and is not capable of converging to the maximum power.

Figure 16 presents the tracking performance of the proposed GSO algorithm under varying radiance conditions. The figure shows the output power of the PV module and boost converter, which is coupled with the load. The change in irradiance, as shown in Figure 15, exhibits sudden mutation at $0.05,0.10,0.15$, and $0.20 \mathrm{~s}$.

As shown in Figure 16, the proposed GSO algorithm can accurately track the MPP of the PV module under variable irradiance. The power losses of the system are $2.43 \%, 2.3 \%$, $2.32 \%, 2.5 \%$, and $2.41 \%$. The output current and output voltage of the PV module are shown in Figure 17.

\section{Conclusion}

The MPPT control strategy based on the GSO algorithm is implemented in this work. The GSO algorithm is a new type of bioinspired algorithm that is employed for the maximum power tracking of PV systems. The control mechanism involves optimizing the reference voltage of the PV module using the proposed GSO, adjusting the operating voltage through the boost converter, and finally allowing the system to work at the MPP. The proposed control scheme 


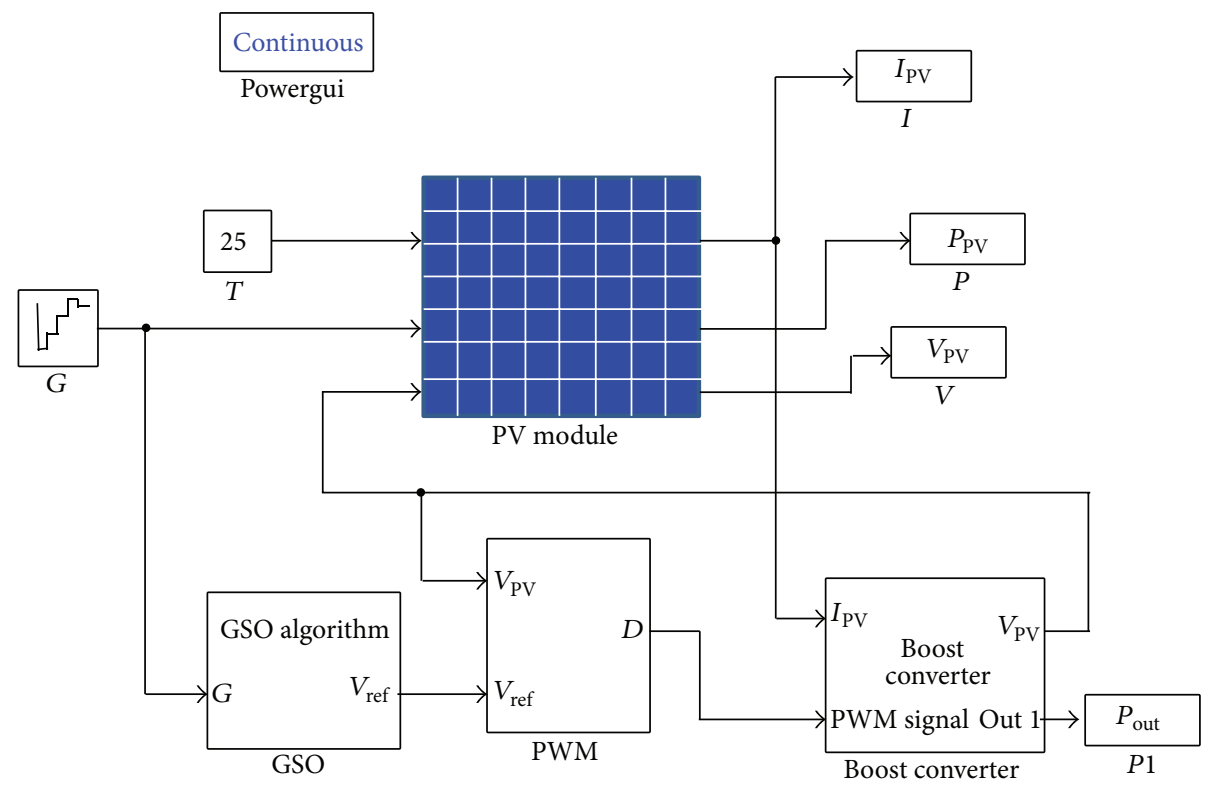

FIGURE 11: Simulation of GSO approach for the considered PV.

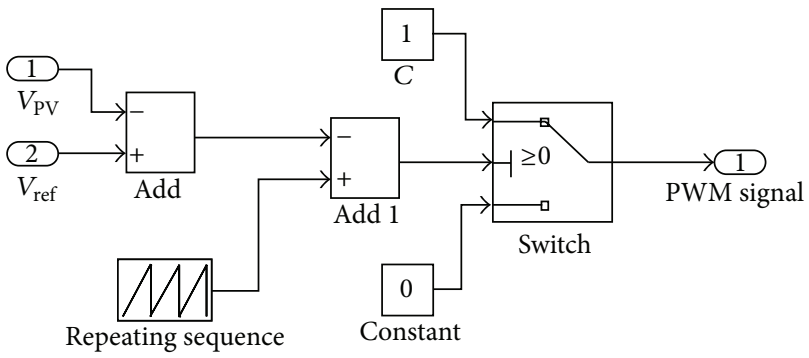

FIGURE 12: PWM intersect in SIMULINK.

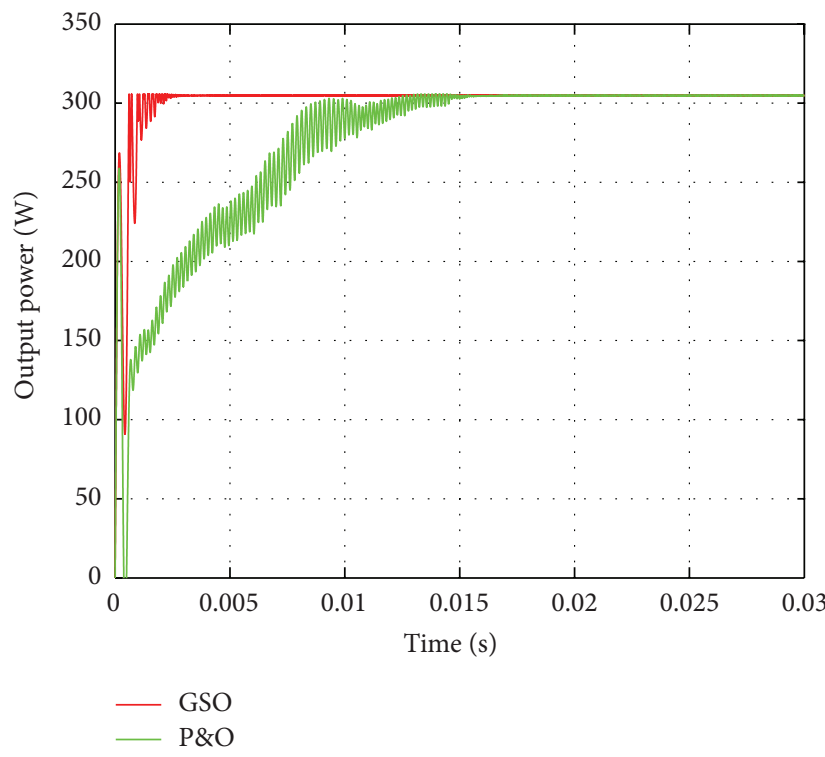

FIgURE 13: Output power of the PV module for the GSO method and $\mathrm{P} \& \mathrm{O}$ method under $1000 \mathrm{~W} / \mathrm{m}^{2}, 25^{\circ} \mathrm{C}$.

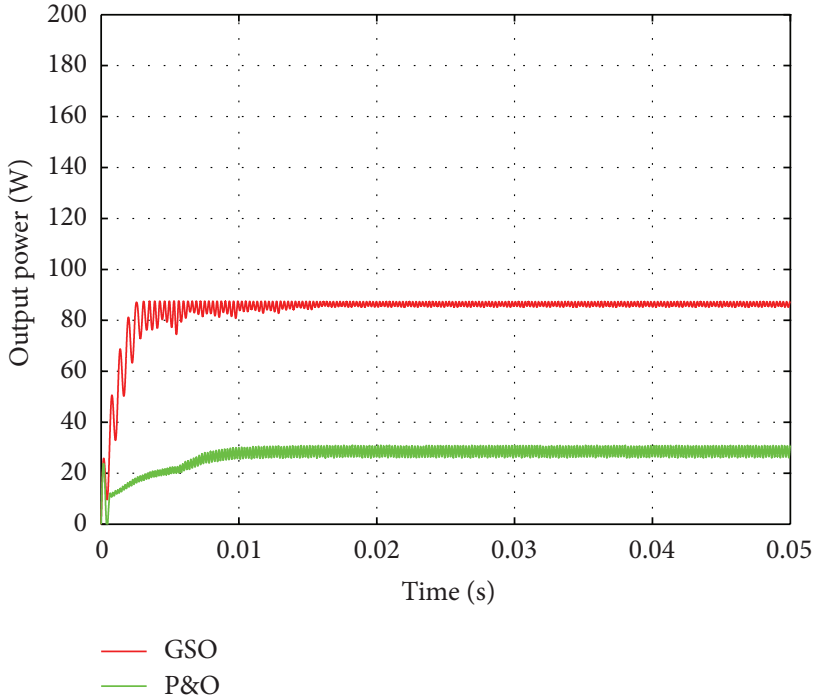

FIGURE 14: Output power of the PV module for the GSO method and $\mathrm{P} \& \mathrm{O}$ method under $300 \mathrm{~W} / \mathrm{m}^{2}, 25^{\circ} \mathrm{C}$.

is verified using SIMULINK. The simulation results indicate that the scheme can track the MPP under constant irradiance and determine the MPP under changing irradiance. Thus, minimal power loss occurs after connecting with the load. The results of the GSO algorithm at constant irradiance are compared with those of the traditional $\mathrm{P} \& \mathrm{O}$ algorithm. The tracking speed and precision of the proposed method are obviously higher than those of the $\mathrm{P} \& \mathrm{O}$ method, particularly at low irradiance. Hence, the control strategy based on the GSO algorithm can be utilized for the MPPT of PV systems. 


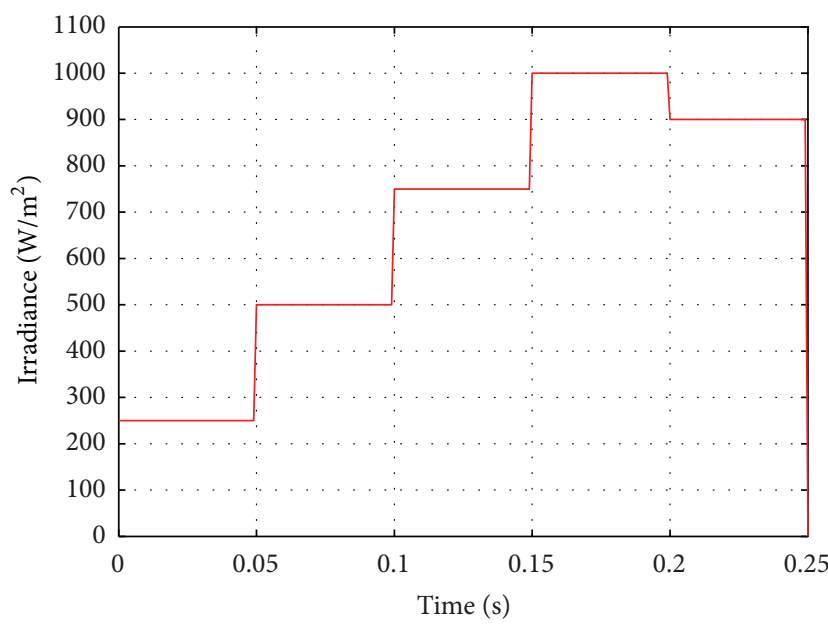

FIgURE 15: Condition of variable radiance.

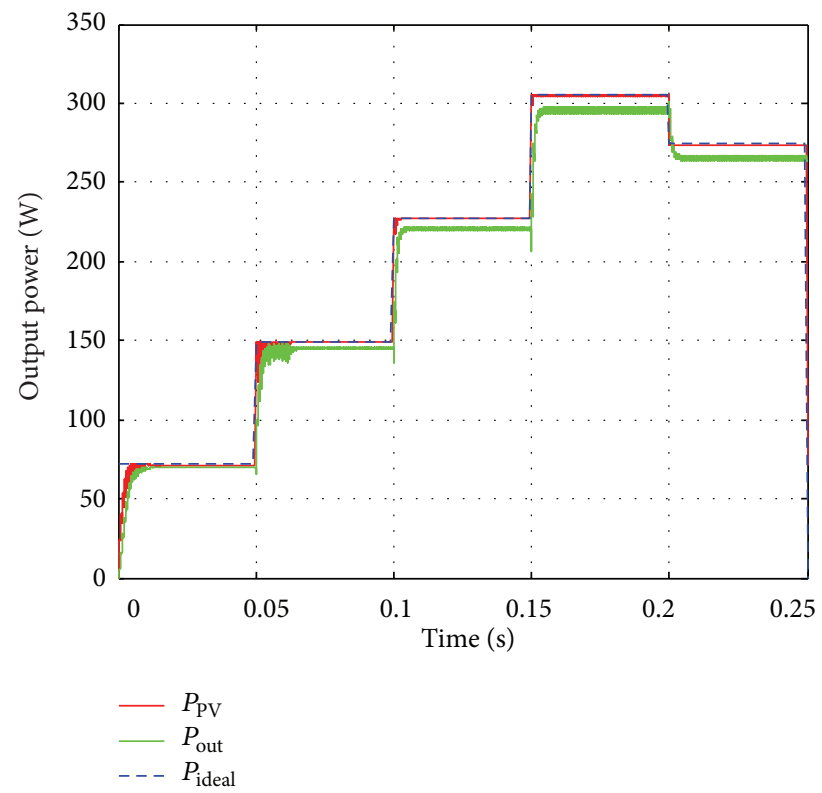

Figure 16: Output power of the PV and boost converter under variable irradiance.

\section{Nomenclature}

A: Diode ideality factor

$d_{i j}$ : Euclidean distance between $i$ and $j$

$D$ : Switch duty cycle

$E_{g}$ : Band gap energy of semiconductor

$F$ : Objective function

$G$ : Relative radiance coefficient

$G_{n}$ : Voltage gain of boost converter

I: PV output current (A)

$I_{d}$ : Diode current (A)

$I_{i}$ : Luciferin of glowworm $i$

$I_{O}$ : Diode reverse saturation current $(\mathrm{A})$

$I_{\mathrm{ph}}$ : Light-generated current $(\mathrm{A})$

$I_{\mathrm{ro}}$ : Diode reverse saturation current at STC

(A)

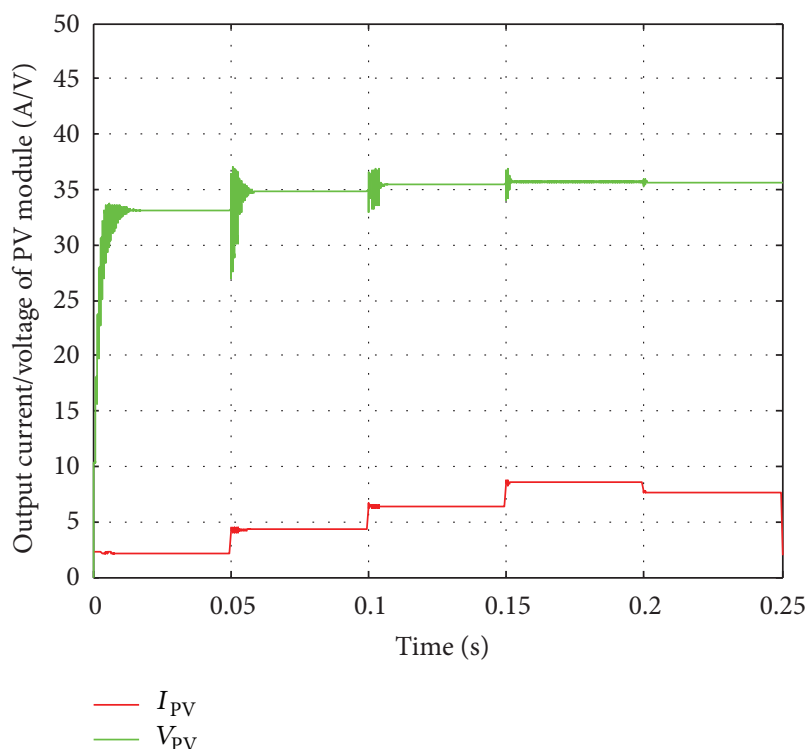

FIGURE 17: Output current and voltage of PV under variable irradiance.

$I_{\text {sc }}: \quad$ Short-circuit current (A)

$I_{\text {sh }}: \quad$ Parallel resistance current (A)

$k: \quad$ Boltzmann's constant $(\mathrm{J} / \mathrm{K})$

$K_{I}$ : $\quad$ PV cell's short-circuit current temperature coefficient

$n_{t}$ : Number of outstanding individuals

$N_{i}(t)$ : Neighborhood of agent

$N_{s}: \quad$ Number of series cells

$P_{i j}$ : Probability of glowworm $i$ moving to $j$

$P_{\max }:$ PV maximum power $(\mathrm{W})$

$P_{\mathrm{PV}}: \quad \mathrm{PV}$ output power $(\mathrm{W})$

$q$ : $\quad$ Electronic charge $(\mathrm{C})$

$r_{d}^{i}$ : Local-decision radius

$r_{s}: \quad$ Largest sensing radius

$R_{p}: \quad$ Parallel resistance

$R_{s}$ : $\quad$ Series resistance

$s: \quad$ Movement step size

$S: \quad$ Solar radiation $\left(\mathrm{W} / \mathrm{m}^{2}\right)$

$t$ : Iteration number

$T_{c}: \quad$ Operating temperature $(\mathrm{K})$

$T_{r}: \quad$ Reference temperature (K)

$U: \quad$ PV output voltage (V)

$U_{d}:$ Diode voltage

$U_{\text {in }}$ : Boost converter input voltage $(\mathrm{V})$

$U_{\text {out }}$ : Boost converter output voltage $(\mathrm{V})$

$U_{\text {oc }}$ : Open-circuit voltage

$x_{i}$ : $\quad$ Location of glowworm $i$.

\section{Greek Symbols}

$\beta$ : Variation coefficient of decision radius

$\gamma$ : Luciferin enhancement constant

$\rho$ : Luciferin decay constant. 


\section{Competing Interests}

The authors declare that they have no competing interests.

\section{Acknowledgments}

The study was sponsored by National Basic Research Program of China (973 Program) (2014CB049500), the National Science Foundation of China (Grant no. 51408578), and Anhui Provincial Natural Science Foundation (1508085QE96 and 1508085QE83).

\section{References}

[1] M. A. Eltawil and Z. Zhao, "MPPT techniques for photovoltaic applications," Renewable and Sustainable Energy Reviews, vol. 25, pp. 793-813, 2013.

[2] M. F. N. Tajuddin, M. S. Arif, S. M. Ayob, and Z. Salam, "Perturbative methods for maximum power point tracking (MPPT) of photovoltaic (PV) systems: a review," International Journal of Energy Research, vol. 39, no. 9, pp. 1153-1178, 2015.

[3] B. Subudhi and R. Pradhan, "A comparative study on maximum power point tracking techniques for photovoltaic power systems," IEEE Transactions on Sustainable Energy, vol. 4, no. 1, pp. 89-98, 2013.

[4] M. A. Elgendy, B. Zahawi, and D. J. Atkinson, "Assessment of perturb and observe MPPT algorithm implementation techniques for PV pumping applications," IEEE Transactions on Sustainable Energy, vol. 3, no. 1, pp. 21-33, 2012.

[5] A. Pandey, N. Dasgupta, and A. K. Mukerjee, "Highperformance algorithms for drift avoidance and fast tracking in solar MPPT system," IEEE Transactions on Energy Conversion, vol. 23, no. 2, pp. 681-689, 2008.

[6] A. K. Abdelsalam, A. M. Massoud, S. Ahmed, and P. N. Enjeti, "High-performance adaptive Perturb and observe MPPT technique for photovoltaic-based microgrids," IEEE Transactions on Power Electronics, vol. 26, no. 4, pp. 1010-1021, 2011.

[7] K. S. Tey and S. Mekhilef, "Modified incremental conductance MPPT algorithm to mitigate inaccurate responses under fastchanging solar irradiation level," Solar Energy, vol. 101, pp. 333342, 2014.

[8] S. S. Mohammed and D. Devaraj, "Simulation of incremental conductance MPPT based two phase interleaved boost converter using MATLAB/simulink," in Proceedings of the IEEE International Conference on Electrical, Computer and Communication Technologies (ICECCT '15), pp. 1-6, Coimbatore, India, March 2015.

[9] P. Mohanty, G. Bhuvaneswari, R. Balasubramanian, and N. K. Dhaliwal, "MATLAB based modeling to study the performance of different MPPT techniques used for solar PV system under various operating conditions," Renewable and Sustainable Energy Reviews, vol. 38, pp. 581-593, 2014.

[10] A. K. Rai, N. D. Kaushika, B. Singh, and N. Agarwal, "Simulation model of ANN based maximum power point tracking controller for solar PV system," Solar Energy Materials \& Solar Cells, vol. 95, no. 2, pp. 773-778, 2011.

[11] H. Rezk and E.-S. Hasaneen, "A new MATLAB/Simulink model of triple-junction solar cell and MPPT based on artificial neural networks for photovoltaic energy systems," Ain Shams Engineering Journal, vol. 6, no. 3, pp. 873-881, 2015.
[12] L. Zaghba, N. Terki, A. Borni, and A. Bouchakour, "Intelligent control MPPT technique for PV module at varying atmospheric conditions using MATLAB/SIMULINK," in Proceedings of the International Renewable and Sustainable Energy Conference (IRSEC '14), pp. 661-666, Ouarzazate, Morocco, October 2014.

[13] B. Bendib, H. Belmili, and F. Krim, "A survey of the most used MPPT methods: conventional and advanced algorithms applied for photovoltaic systems," Renewable and Sustainable Energy Reviews, vol. 45, pp. 637-648, 2015.

[14] P. S. Samrat, F. F. Edwin, and W. Xiao, "Review of current sensorless maximum power point tracking technologies for photovoltaic power systems," in Proceedings of the International Conference on Renewable Energy Research and Applications (ICRERA '13), pp. 862-867, IEEE, Madrid, Spain, October 2013.

[15] F. Mangiatordi, E. Pallotti, P. Del Vecchio, and F. Leccese, "Power consumption scheduling for residential buildings," in Proceedings of the 11th International Conference on Environment and Electrical Engineering (EEEIC '12), pp. 926-930, Venice, Italy, May 2012.

[16] C. Larbes, S. M. Aït Cheikh, T. Obeidi, and A. Zerguerras, "Genetic algorithms optimized fuzzy logic control for the maximum power point tracking in photovoltaic system," Renewable Energy, vol. 34, no. 10, pp. 2093-2100, 2009.

[17] M. Bechouat, Y. Soufi, M. Sedraoui, and S. Kahla, "Energy storage based on maximum power point tracking in photovoltaic systems: a comparison between GAs and PSO approaches," International Journal of Hydrogen Energy, vol. 40, no. 39, pp. 13737-13748, 2015.

[18] T. Sudhakar Babu, N. Rajasekar, and K. Sangeetha, "Modified particle swarm optimization technique based maximum power point tracking for uniform and under partial shading condition," Applied Soft Computing Journal, vol. 34, pp. 613-624, 2015.

[19] R. B. A. Koad and A. F. Zobaa, "Comparison between the conventional methods and PSO based MPPT algorithm for photovoltaic systems," International Journal of Electrical, Computer, Energetic, Electronic and Communication Engineering, vol. 8, no. 4, 2014.

[20] S. S. Mohammed and D. Devaraj, "Simulation and analysis of stand-alone photovoltaic system with boost converter using MATLAB/Simulink," in Proceedings of the International Conference on Circuits, Power and Computing Technologies (ICCPCT '14), pp. 814-821, Nagercoil, India, March 2014.

[21] D. Rekioua, A. Y. Achour, and T. Rekioua, "Tracking power photovoltaic system with sliding mode control strategy, Energy Procedia, vol. 36, pp. 219-230, 2013.

[22] H. Cui, J. Feng, J. Guo, and T. Wang, "A novel single multiplicative neuron model trained by an improved glowworm swarm optimization algorithm for time series prediction," KnowledgeBased Systems, vol. 88, pp. 195-209, 2015.

[23] K. N. Krishnanand and D. Ghose, "Glowworm swarm optimization for simultaneous capture of multiple local optima of multimodal functions," Swarm Intelligence, vol. 3, no. 2, pp. 87124, 2009. 

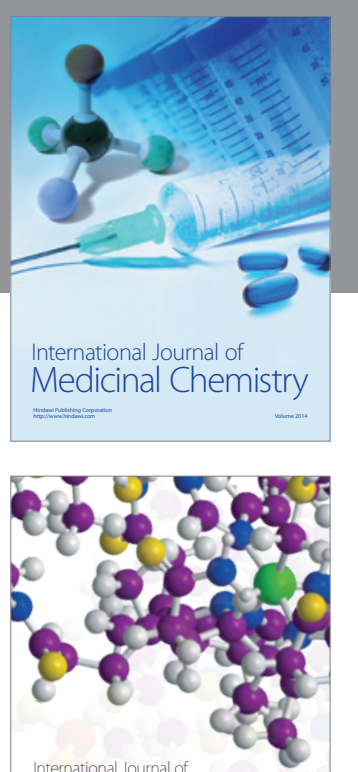

Carbohydrate Chemistry

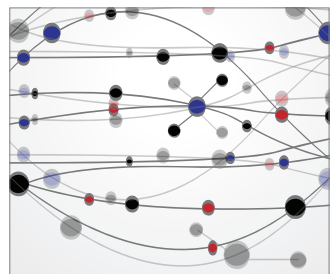

The Scientific World Journal
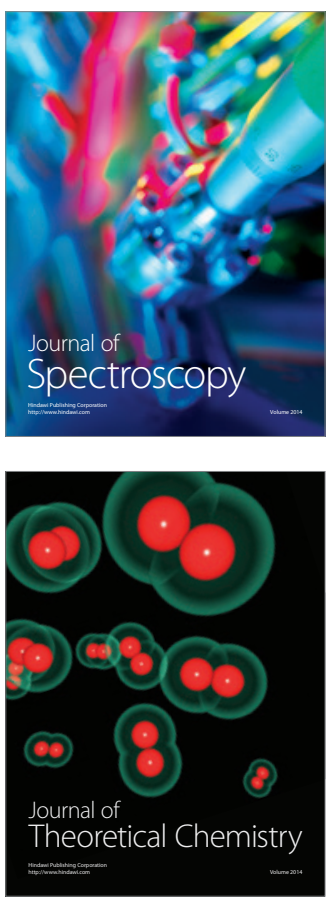
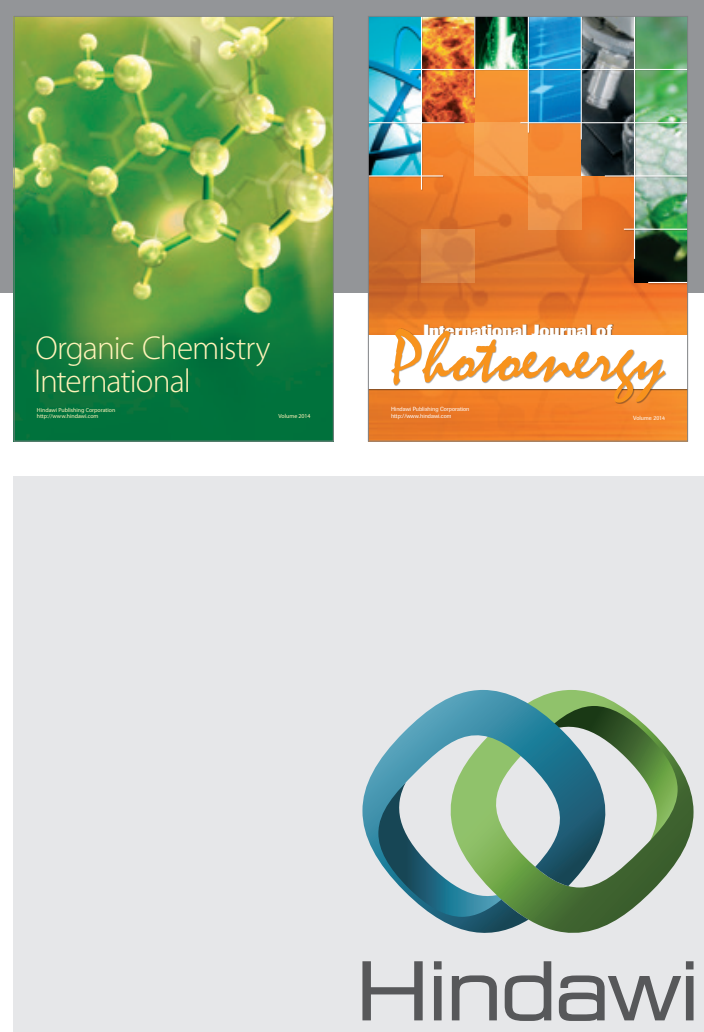

Submit your manuscripts at

http://www.hindawi.com

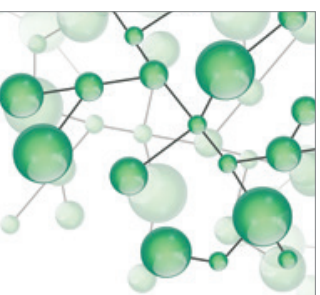

International Journal of

Inorganic Chemistry

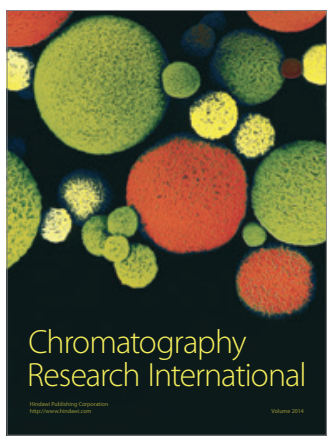

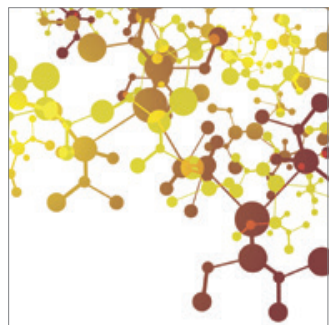

Applied Chemistry
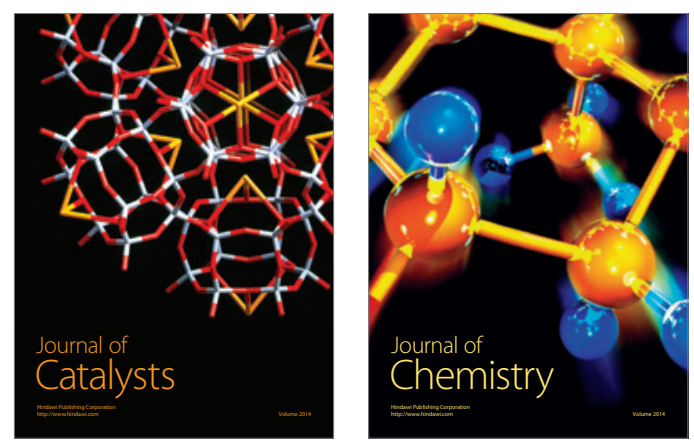
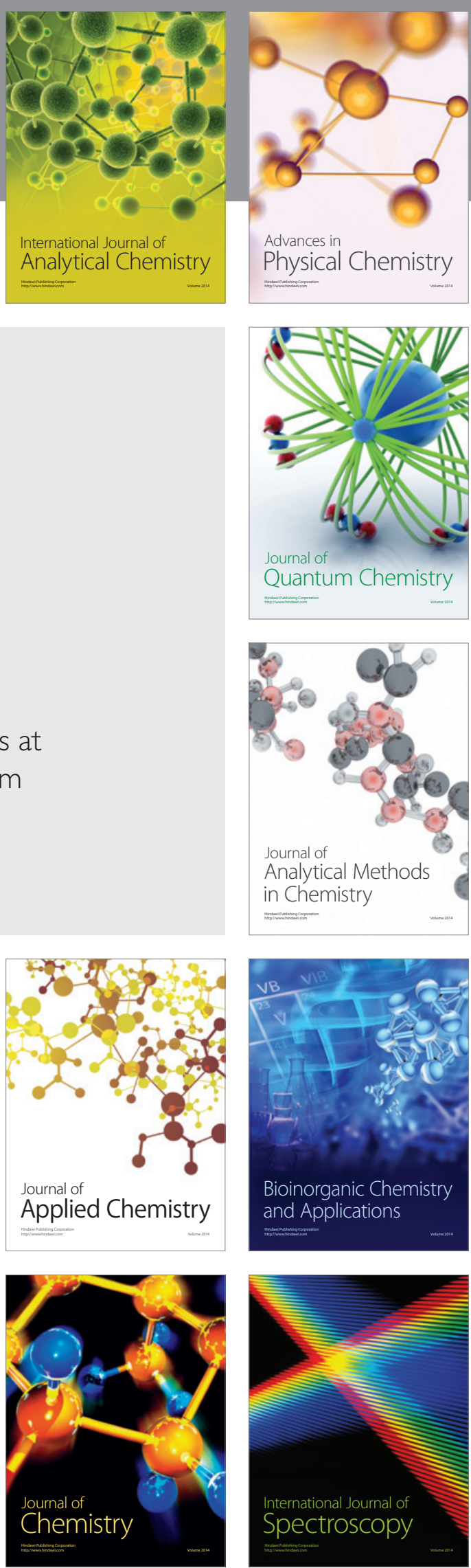